\title{
Prevalence of Major Skin Diseases in Ruminants and its Associated Risk Factors at University of Gondar Veterinary Clinic, North West Ethiopia
}

Daniel Teshome* and Samuel Derso

Faculty of Veterinary Medcine, University Of Gondar, Gondar, Ethiopia

*Corresponding author: Daniel Teshome, Faculty of Veterinary Medcine, University of Gondar, Gondar, Ethiopia, Tel: +251913594781; E-mail: dteshome11@gmail.com Rec date: May 30, 2015; Acc date: Sep 28, 2015; Pub date: Sep 30, 2015

Copyright: $\odot 2015$ Teshome D, et al. This is an open-access article distributed under the terms of the Creative Commons Attribution License, which permits unrestricted use, distribution, and reproduction in any medium, provided the original author and source are credited.

\begin{abstract}
A cross sectional study was carried out during the period between November, 2013 to April, 2014 to determine the prevalence of major skin disease and to identify the dominant risk factors for this disease in Gondar university veterinary clinic. A total of 1296 ruminants that came to the Clinic were involved in the study. Out of this $513(39.6 \%)$ cattle, 631(48.7\%) sheep and 152(11.7\%) goat was included. Skin scraping, morphological identification and clinical presentation were the methods employed for identification of mange mites and Dermatophilosis, gross ectoparasites and viral skin disease respectively. 468(36.1\%) were infested with one or more skin diseases. The prevalence of skin diseases in cattle, sheep and goats were $142(27.68 \%), 268(42.47 \%)$ and $58(38.12 \%)$ respectively. The difference in the prevalence of skin diseases among the three host species was statistically significant $(p<0.05)$. The major skin diseases identified on ruminants were tick 116(8.95\%), mange 31(2.39\%), lice 91(7.02\%), sheep ked $72(5.56 \%)$, lumpy skin disease $29(2.24 \%)$, Dermatophilosis $9(0.69 \%)$, orf $45(3.47 \%)$ and sheep and goat pox $77(5.94 \%)$. The prevalences of ectoparasites at genus level were tick (BoophilusHyalomma, Amblyommaand Rhipicephalus), mange mite (Demodex, Sarcoptesand Psoroptes) and Lice (Damalina and Linognathus). The difference in the prevalence of skin disease infestation between poor and good body condition was statistically significant in ruminants $(\mathrm{P}<0.001)$. The predilation site of skin disease were tick in hairless area, mange mite and lice in neck and head areas, Dermatophilosis on the back, orf in face region of, sheep ked in hairy parts of sheep, lumpy skin disease and sheep and goat pox in whole body parts of cattle and small ruminants. The study demonstrates that skin disease is among the most important health constraints of ruminants in and around Gondar town, hence requires immediate attention and control interventions.
\end{abstract}

Keywords: Prevalence; Risk factor; Ruminants; Skin disease

\section{Introduction}

Ethiopia has the largest livestock inventories in Africa, including, about 53.99 million cattle, 25.5 million sheep, 24.06 million goats, 1.91 million horses, 6.75 million donkeys, 0.35 million mules, 0.92 million camels and about 50.38 million poultry are estimated to find in the country [1]. It performs multiple functions in the Ethiopian economy by providing food, input for crop production and soil fertility management, raw material for industry, cash income as well as in promoting saving, fuel, social functions and employment. The sector's contribution to national output is underestimated, because traction power and manure for fertilizer are not valued. Livestock Contributes $12-15 \%$ of total export earnings, the sub-sector is the second major source of foreign currency through export of live animals, meat, hides and skins [2]. At the household level, livestock contributes to the livelihood of approximately 70 percent of Ethiopians. Women play a critical role in livestock production, both directly in primary production of small ruminants, and indirectly through the contribution of livestock to household assets. Livestock offers a particular package of benefits to pastoralists, for whom few alternative livelihoods exist [3]. Hides and skins averaged a yearly export value of $\$ 52,160,000$ USD, livestock averaged $\$ 3,390,000$ USD, and meat $\$ 2,380,000$ USD. Over this twenty-one year period, hides and skins provided on average $90 \%$ of official livestock sector exports, livestock provided $6 \%$ and meat $4 \%$. For a time in the 1990 's, hides, skins and leather were Ethiopia's second largest export earner after coffee [4].
Despite the large number of livestock, there has been a decline in national and per capita production of livestock and livestock products, export earnings from livestock and per capita consumption of food from livestock origin in comparison to other African countries due to disease and other constraints [2].

Even if much number of tanneries is involved in production of finished and semi-finished leather products, the sector and the country are losing revenue due to a decline in leather quality. A considerable portion of these pre-slaughter defects are directly related to skin diseases or secondary damage that occurs when the animal scratches itself to relieve the itching associated with some of these diseases [5]. The existence of various skin diseases affecting ruminants is frequently reported from different parts of Ethiopia. These different skin diseases in Ethiopia are accountable for considerable economic losses particularly to the skin and hide export due to various defects, $65 \%$ of which occur in the pre slaughter states directly related mostly to skin disease and skin and hides are often rejected because of poor quality. The most common ruminant skin diseases reported in Ethiopia are Dermatophilosis, lumpy skin disease, pediculosis, acariasis, ked, sheep and goat pox and orf [6].

Apart from quality degradation of skin and hides, skin diseases induce associated economic losses due to reduction of wool quality, meat and milk yield, losses as a result of culling and occasional mortalities and related with cost of treatment and prevention of the diseases. Some skin problems are easy to cure others more complicated and some like ring worm are even highly contagious to the human 
handlers. The effect of skin problems on animal productivity also varies from mild irritations to rapid death [7].

External parasites are the most serious threat since they feed on body tissues such as blood, skin and hair. More significant, however, is that any blood-sucking arthropod may transmit diseases from infected animals to healthy ones. In addition, arthropod pests also may reduce weight gains, produce general weakness, severe dermatitis, and create sites for secondary invasion of disease causing organisms. In general, infected livestock cannot be healthy or efficiently managed to realize optimum production levels [8].

The potential economic loss the country is experiencing necessitates the nation-wide detailed investigation on the distribution of important skin disease. Since Ethiopia is known to be use and export ruminant skin among the livestock it has, it is necessary to study the disease which affects the skin of those animals. Even though the prevalence of different skin disease are investigated in different parts of Ethiopia; yet there is no research conducted that shows prevalence of major skin diseases in ruminants and its associated risk factors at Gondar university veterinary clinic. Therefore the objectives of this thesis are:

To determine the prevalence of major ruminant skin disease in and around University of Gondar veterinary clinic.

To assess the relationship among different risk factors with the occurrence of ruminant skin disease.

To identify the different risk factors for skin diseases occurrence in the study area.

\section{Material and Methods}

\section{Study area}

A cross sectional study were conducted from November, 2013 to April, 2014 in Gondar University veterinary clinic at Gondar town which is the Capital city of North Gondar zone in Amhara regional state. It is located $740 \mathrm{~km}$ northwest of the capital city, Addis Ababa. It is situated between $12^{\circ} 36^{\prime} \mathrm{N}$ and $33^{\circ} 28^{\prime} \mathrm{E}$ at an altitude of about $2300 \mathrm{~m}$ above sea level (m.a.s.l) with an average temperature of $20^{\circ} \mathrm{C}$ and an average annual rainfall of $1800 \mathrm{~mm}$. Being a highland area, the city is spread on different mountains, slopes and in valleys and has three small rivers, many streams and a lake. Gondar is the place which is rich in different tourism investment that attracts many tourists from abroad and different places of Ethiopia. These heritages include Fasile castle, Dashen Mountain with its endemic animals that are wallia ibex and red fox, Debrebirhan Silasie, Qusquam church and etc., The human population size of Gondar town in 2008 is about 112,249. Out of which 60,883 are males and 51,366 are females. The livestock population in the area comprises of cattle $(8,202)$, goat $(22,590)$, sheep $(2,695)$, horse $(1,065)$ and donkey $(9,001)(\mathrm{CSA}, 2008)$. These animals in and around Gondar is used for traction power, meat and milk production and for transportation of materials and man from place to place.

\section{Study animals}

The study animals were cattle, sheep and goat that had brought to Gondar university veterinary clinic and it include sex, all breeds and all age groups weather they are from intensive or extensive farming system. The age of the animals will be determined primarily based on the information obtained from the owners and also by looking the dentition pattern of animals. Animals were divided into two groups according to their age, namely young (less than or equal to 2 year old) and adult animals (above 2 year old) [9].

\section{Study methodology}

Clinical examination: In this study, animals were sampled during sample collections and the related risk factors such as sex, age, breed, body condition, species, season and managemental conditions were recorded before sampling. The tags of study animals were properly recode during sampling and then each animal were also carefully inspect for the skin pathogens. The samples were taken to Gondar University laboratory for identification. Clinical skin disease investigations were conducted by examination of skin of each animal through visual inspection and palpation. For positive cases on clinical examination, detailed husbandry and health history were taken from the owner of the animals. Depending upon the clinical presentation of skin diseases, samples such as, skin-scrapings, hair specimens, pustules, abscesses and externally visible parasites were collected and subjected to a proper laboratory investigation. Viral infections like Lumpy Skin Disease (LSD) and Pox Disease were diagnosed based on their occurrence in a flock and observable clinical pictures such as wide spread skin lesions on and around the muzzle, ears, scrotum and udder [10].

Laboratory investigation: Specimen of hair plus skin will plucked from lesions suspected of dermatophytosis using forceps, put in dry Petri dish and transport to the laboratory to demonstrate characteristic disease causing agent from lesion scraping. Deep scrapings of pustules and abscess were collected for demodicosis suspected cases and smears of their content were examined for the presence of demodectic mites at 10x magnification of light microscope [11]. For the mange mite infestations, skins crapings (till capillary blood oozes) were taken from the periphery of active lesions. The specimens were placed in test tubes and were treated by $10 \mathrm{ml} \mathrm{KOH} \mathrm{(10 \% )} \mathrm{and} \mathrm{examined} \mathrm{based} \mathrm{on} \mathrm{the}$ standard procedures [12]. Exudative crusts were taken by pairs of forceps and were transport to the laboratory in dry Petri dish where they are subjected to Giemsa staining for demonstration of Dermatophilus congolensis. Lice and tick were collected in $70 \%$ alcohol by parting the hair and were identified using the standard procedures.

Data management and analysis: A cross-sectional study was conducted to determine the current prevalence of major skin diseases in the study area. The total numbers of ruminants that were attended in Gondar university veterinary clinic from November to April were sampled. After Data collection it was recorded in Microsoft excel spread sheet and preliminary analysis were done in it. The laboratory data were coded and the associations of risk factors with the occurrence of the diseases were assess using Chi-square and Fisher's Exact Test. The Chi-square $\left(\mathrm{X}^{2}\right)$ test was used to assess differences in the prevalence of skin diseases among species, breed, sex, body condition, age groups, management, Predilation site and season of diseases occurrence. All statistical analyses were conducted using SPSS (Version 16) statistical software and $\mathrm{p}<0.05$ were taken as significance [13]. 
Citation: Teshome D, Derso S (2015) Prevalence of Major Skin Diseases in Ruminants and its Associated Risk Factors at University of Gondar Veterinary Clinic, North West Ethiopia. J Veterinar Sci Technol S: S13-002. doi:10.4172/2157-7579.1000S13-002

Page 3 of 7

\section{Result}

\section{Over all prevalence of skin diseases in ruminants (cattle, sheep and goat)}

A total of 1296 ruminants were examined to determine the prevalence of major skin disease in Gondar university veterinary clinic. Of these, $468(36.1 \%)$ were primarily infested by skin disease or infested with skin diseases secondary to other systemic disease. The overall prevalence of skin diseases in cattle, sheep and goats were $142(27.68 \%), 268(42.47 \%)$ and $58(38.16 \%)$ respectively. The difference in the prevalence of skin diseases among the three host species was statistically significant $(\mathrm{p}<0.05)$. From the total animal population examined 628(48.45\%) male and 668(51.54) female were included in the examination. Some skin disease were most common to one of ruminant host; as result sheep ked is found only in sheep and lump skin disease was found only in cattle during the study. In addition to this orf and sheep and goat pox was found mainly in sheep and goat.

Ectoparasite covers $65.81 \%$ and the remaining $34.19 \%$ were other infectious disease. The major ectoparasites identified on ruminants were tick 116(37.66\%), mange 32(10.38\%), lice 91(29.55\%) and sheep ked $72(23.38 \%)$.The main ectoparasite at genus level were tick (Boophilus42(13.63\%), Hyaloma 39(12.66\%), Amblyoma 23(7.46\%) and Rhipicephalus 12(3.89\%)), mange mite [Demodex 13(4.22\%), Sarcoptes 12(3.89\%) and Psoroptes $7(2.27 \%)$ ] and Lice [Damalina 45(14.61\%) and Linognatus 43(13.96\%)]. However, there was no statistical significant variation $(\mathrm{P}>0.05)$ among the three host species of ectoparasite infestation except sheep ked which was specifically affect sheep and it had statistically significant $(\mathrm{P}<0.001)$ with the occurrence on sheep.

Other bacterial and viral disease which affects skin was covered $34.14 \%$; those were Lumpy skin disease 29(18.12\%), Dermatophilosis $9(5.62 \%)$, orf $45(28.12 \%)$ and sheep and goat pox $77(48.12 \%)$. The occurrence of lumpy skin disease, sheep and goat pox and orf had statistical significance association $(\mathrm{P}<0.001)$ with ruminant animal; while the prevalence of dermatophilosis has not significant association $(\mathrm{P}>0.05)$ with ruminant species.

With regard to age wise comparison, among the 1296 animals examined $526(40.7 \%)$ and $768(59.3 \%)$ were young and adult ruminants respectively; from these animals 204(15.74) young and 104(8.024) adult ruminants were positive for skin disease. Young ruminants were susceptible to skin diseases than the adult age group; as a result the infection rate among the two age categories were statistically significant $(\mathrm{P}<0.05)$.

\section{Prevalence of skin diseases in cattle:}

The overall prevalence of skin diseases in cattle was $14227.68 \%$ ) from 513 cattle examined; of which 69(13.45\%) male and 73(14.23\%) female. All animals were mono-infected and ectoparasites were responsible for $72.54 \%$; while $27.46 \%$ was attributed to other skin diseases. The common infestation sites of lice were the shoulder, neck, sides and back regions where as the most common infestation area of tick, dermatophilosis, mange mite and lumpy skin disease were soft skin area like (scrotem, ventral body part and anus), back side of the animal, head and neck region and whole body parts of cattle respectively. $42.58 \%$ young, $17.43 \%$ adult, $33.81 \%$ local breed, $45.16 \%$ cross breed, $26.19 \%$ good body condition, $21.78 \%$ medium body condition and $64.12 \%$ poor body condition cattle were infected with skin disease. Young, cross breed and poor body condition cattle were more affected by skin disease than adult, local breed, good and medium body condition cattle; this has statistically significant association $\left(X^{2}=39.132\right.$ and $p<0.001, X^{2}=17.34$ and $p<0.001$ and $\mathrm{X}^{2}=51.65$ and $\mathrm{P}<0.001$ respectively) with disease occurrence. Skin disease of cattle had not significant association with sex of the animal, season of disease occurrence and husbandry/management of the animal except dermatophilosis and lumpy skin disease which were common at the beginning of winter and mid spring season respectively.

The major skin diseases occurring in cattle were infestation by ticks (10.53\%), pediculosis (7.21\%), lumpy skin disease (5.65\%), mange mite infestation (2.34\%) and dermatophilosis (1.36\%); in which $5.85 \%$ poor body condition, $1.12 \%$ medium body condition $3.51 \%$ good body condition; $4.68 \%$ cross breed and $5.85 \%$ local breed;7.02\% young and $3.51 \%$ adult cattle were infected with tick. Young, poor body conditioned and local breed cattle were more susceptible to tick than adult, medium and good body conditioned and cross breed animals respectively. Tick infestation had been highly significant association $(\mathrm{p}<0.001)$ with age, body condition and breed of cattle. $0.97 \%, 0.19 \%$ and no cattle; that had poor, medium and good body condition were infected by demodicosis respectively. Demodex infection has significant association $(\mathrm{P}<0.001)$ with body condition. Sarcoptes and lice infestation had significance association $(\mathrm{p}<0.05)$ with body condition and age of the cattle respectively with prevalence rate of $4.87 \%$ young and $2.34 \%$ adult for lice infestation and $0.78 \%$ poor body condition, $0.19 \%$ medium body condition and no good body condition Sarcoptes infection were prevalent in cattle. All dermatophilosis positive animal were female and it has significant association $(\mathrm{p}<0.05)$ with sex of the animal while the other skin disease had not significant association ( $p>0.05)$ with sex, age, body condition score and breed of cattle.

\section{Prevalence of skin diseases in small ruminants (Sheep and Goats)}

Out of 309 male and 322 female sheep and 77 male and 75 female goats examined, 268 sheep $(42.47 \%)$ and 58 goats (38.16\%) exhibited skin diseases: among these 126(40.77\%) male and $142(44.1 \%)$ female and $27(35.06 \%)$ male and $31(41.33 \%)$ female sheep and goat respectively. The skin disease was more frequently observed in young animals than in adults $\left(X^{2}=76.586, p<0.001\right.$ for sheep; $X^{2}=25.156$, $\mathrm{p}<0.001$ for goats) and in poor body condition than in good and medium body condition animals $\left(\mathrm{X}^{2}=11.326, \mathrm{p}<0.05\right.$ for goats and $\mathrm{X}^{2}=23.388, \mathrm{p}<0.001$ for sheep). Among diseased small ruminants, 176 sheep $(27.89 \%)$ were infected by one or more ectoparasites: 109 (17.27\%) sheep were infected with only one ectoparasites while $67(10.62 \%)$ sheep were poly-infected mainly by tick and sheep ked whereas only mono-infestations were encountered in the $31(20.39 \%)$ goats with ectoparasites and the remaining 27 (17.76\%) were infected with other viral and bacterial skin diseases.

The common area of these ectoparasite was anterior body part (neck, ear, face and thorax region), hair less region (scrotem, inguinal area, tough and around the umbilicus), head and tail region (face, ear, neck, tail and rump) of sheep and goat for lice, tick and mange mite respectively. No significant association $(p>0.05)$ between sex and susceptibility to skin disease infestation was demonstrated in sheep, in goats or in the overall population. There was no significant association ( $p>0.05)$ between species of sheep and goat for ectoparasite infestation except sheep ked which was totally found in the hairy body part of 
Citation: Teshome D, Derso S (2015) Prevalence of Major Skin Diseases in Ruminants and its Associated Risk Factors at University of Gondar Veterinary Clinic, North West Ethiopia. J Veterinar Sci Technol S: S13-002. doi:10.4172/2157-7579.1000S13-002

Page 4 of 7

sheep and there was high significant association $(\mathrm{p}<0.001)$ between sheep ked infection and ovine species.

Prevalence of skin diseases in sheep: Among the sheep that brought to Gondar university clinic, high proportion $(51.03 \%)$ was covered by female and the remaining $(48.96 \%)$ was male. The prevalence of skin disease in according to different risk factor relation was $61.12 \%$ in young and $28.15 \%$ in adult, $25 \%$ in good, $40.53 \%$ in medium and $63.3 \%$ in poor body condition sheep, $0.23 \%$ in spring, $18.3 \%$ in ottoman and $29.32 \%$ in winter season. Poor body condition and young sheep were frequently affected than good and medium body condition and adult sheep. In winter season sheep were more affected than in spring and ottoman season. Age, body condition of sheep and season diseases occurrence has significant relation $\left(\mathrm{X}^{2}=76.586, \mathrm{P}<0.001\right.$ for age, $X^{2}=23.39, p<0$. 001 for body condition and $X^{2}=7.749, p<0.05$ for season) with the prevalence of skin disease of sheep; whereas management and sex had not significance relation $(\mathrm{p}>0.05)$.

During this study young sheep were infected by $5.39 \%$ tick, $0.48 \%$ Psoroptes mange, $4.12 \%$ by lice, $6.97 \%$ by sheep ked and $5.07 \%$ by sheep and goat pox with adult infection rate of $2.38 \%$, no infection rate, $2.23 \%, 4.44 \%$ and $3.8 \%$ by tick, psoroptes mange, lice, sheep ked and sheep and goat pox respectively. These diseases were affect young sheep than adult sheep and there was a significant relationship $(\mathrm{P}<0.001$ in tick, $\mathrm{P}<0.05$ in Psoroptes mange, $\mathrm{P}<0.05$ in lice, $\mathrm{P}<0.001$ in sheep ked and $\mathrm{P}<0.05$ in sheep and goat pox) between age and prevalence of tick, psoroptes mange, lice, sheep ked and sheep and goat pox. Tick, Sarcoptes, Demodex and Psoroptes preferentially affect poor body conditioned than good and medium body condition sheep and there was statistical significance $(\mathrm{P}<0.001$ for tick and $\mathrm{P}<0.5$ for Sarcoptes, Demodex and Psoroptesmanges)between body condition score and occurrence of Tick, Sarcoptes, Demodex and Psoroptes manges).The other skin diseases observed in sheep in this study were sheep and goat pox and contagious ecthyma or orf in sheep with the prevalence rate of $8.87 \%$ and $5.07 \%$ in sheep and goat pox and contagious ecthyma respectively. These viral diseases had not statistically significant association $(\mathrm{P}>0.05)$ with sex, body condition score and age of sheep except sheep and goat pox that were significantly associated $(\mathrm{p}<0.05)$ with age of the animal.

Prevalence of skin diseases in goats: Sex, age, body condition, season and management of the animal were taken as risk factors during this study. $62.29 \%$ young and $21.98 \%$ adult, $30 \%$ good body condition, $32.17 \%$ medium body condition and $66.67 \%$ poor body condition goat were infected with skin diseases. Young and poor body conditioned goat were highly susceptible than adult and good as well as medium body conditioned goat. Age and body condition score were statistically significant $(\mathrm{P}<0.001$ for age and $\mathrm{P}<0.05$ for body condition) with the prevalence of skin disease in goat; while season, sex and management had no significant association $(\mathrm{P}<0.05)$ with skin disease prevalence of goat.

The identified ectoparasites species were $8.55 \%$ lice (Damalina caprae and Linognathus species), 7.24\% tick (Ambylomma, Hyalomma, Boophilus and Rhipicephalus) and 3.29\% mange mite (Demodex, Sarcoptes and Psoroptes). The other skin diseases observed in goats during this study were $8.55 \%$ pox virus disease, $9.21 \%$ contagious ecthyma/orf and $1.34 \%$ dermatophilosis. Among skin diseases positive goats $3.94 \%$ poor body condition, $3.29 \%$ medium body condition and no good body condition animals were positive for goat skin diseases. In case of age categories of goat $5.92 \%$ lice and $5.92 \%$ tick in young and $2.63 \%$; lice and $1.34 \%$ tick in adult were prevalent. Young age and poor body condition goat was highly susceptible to tick than adult, medium and good body conditioned animals. There was significant relation $(\mathrm{P}<0.5)$ between body condition and age of goat with prevalence of tick and statistical significance $(\mathrm{p}<0.05)$ were present between age and prevalence of lice.

\section{Discussion}

This study indicates that skin diseases caused by parasites, bacteria and viruses were common in and around Gondar town in ruminants: their overall prevalence were $10.96 \%, 20.68 \%$ and $4.48 \%$ in cattle, sheep and goats respectively. These relative high frequencies would be associated with nutritional factor, climatic stress, fly season and favorable condition for diseases agent multiplication. As different flocks of animals came in close contact at available communal watering and grazing sites (contact points) because of the feed scarcity, the establishment and spread of skin diseases infections were encouraged. The prevailing poor veterinary services, improper application of acaricides by non-professionals could also amplified this endemic situation.

Furthermore, young animals were significantly more frequently affected than adults $(\mathrm{p}<0.001$ in cattle, in sheep, goat and in the overall ruminants) probably because of their low acquired resistance compared to adults. By contrast, local and cross breeds of cattle which share the same environment the cross breeds were more significantly affected by skin diseases $\left(\mathrm{X}^{2}=17.34\right.$ and $\left.\mathrm{p}<0.001\right)$ than local breed cattle; suggesting that local breeds have developed a specific genetic resistance towards skin diseases. The occurrence of lumpy skin disease, sheep and goat pox and orf had statistical significance association $(\mathrm{P}<0.001)$ with ruminant animal; while the prevalence of dermatophilosis has not significant association $(\mathrm{P}<0.05)$ with ruminant species. This was due to the nature of the virus which selectively attack animals that is sheep and goat pox affects sheep and goat and lumpy skin disease affect mainly cattle. Even if orf affects wide range of animals it affects mostly sheep and goat as a result of flocking nature of the small animal and contact transmission nature of the disease.

Among skin diseases, the prevalence of ectoparasite infestations in my study was important in cattle and sheep (103(7.95\%) and $176(13.58 \%)$ respectively) rarely to goats $29(2.24 \%)$. The prevalence of ectoparasite was not statistically significant $(\mathrm{P}>0.05)$ with ruminant species, except sheep ked which is common parasite for sheep in which prevalence of sheep ked was statistically significant $(\mathrm{P}<0.001)$ with species of ruminants. Higher ectoparasite prevalence was observed in and around Gondar town in small ruminants $(26.18 \%)$; it was also reported that ectoparasites was significantly more frequent $(78.3 \%)$ in small ruminants in and around Gondar town [14]. This reduction of small ruminant infestation from the former one may due to proper control of ectoparasites by animal health servants and good management practice of the owner. There were reports $(68.69 \%$ in sheep and $28.43 \%$ in goats) and $13.80 \%$ in sheep and $7.80 \%$ in goats) from Wollaytasodo and Adama town respectively by Yacob et al. [15]. This difference of small ruminant ectoparasite prevalence may be due to difference in agro ecology and diseases distribution. Furthermore the prevalence of ectoparasite was reported as $55.5 \%$ in sheep and $58 \%$ in goats and $50.5 \%$ in sheep and $56.4 \%$ in goats by Mulugeta et al. [16] and Sertese and Wesen [17] in Tgray region and in different agro ecological zone of eastern Amhara respectively. From the above previous reports the prevalence of ectoparasite in goat was higher than in sheep but in this study the prevalence of ectoparasite in sheep was 
Citation: Teshome D, Derso S (2015) Prevalence of Major Skin Diseases in Ruminants and its Associated Risk Factors at University of Gondar Veterinary Clinic, North West Ethiopia. J Veterinar Sci Technol S: S13-002. doi:10.4172/2157-7579.1000S13-002

Page 5 of 7

higher than goat. This is suggested as a result of disproportion of sample size of the two species in different studying area.

The main ectoparasites were ticks (Ambylomma,Hyalomma, Boophilus and Rhipicephalus species),mange mite (Demodex, Sarcoptes and Psoroptes) and lice (Damalina ovis, Damalina bovis, Damalina caprae and Linognatus species).Tewodros et al (2012) reported the presence of these ectoparasites (Boophilus, Hyalomma, Ambylomma, Demodex, Sarcoptes, Psoroptes, Damalina ovis, Damalina caprae and Linognatus species) in small ruminants of in and around Gondar town.

The prevalence of tick among species was $10.52 \%, 7.77 \%$ and $7.24 \%$ during my study. The main tick attachment sites were ventral abdomen, sternum, under the tail, scrotum in males and udder in females and the tick infestation prevalence was not significantly influenced $(\mathrm{P}>0.05)$ by sex, and season. The same tick species have been identified in the previous study conducted in the Wolaita Soddo region [7] including that Rhipicephalus genus in small ruminants. Tick infestation had been highly significant association $(\mathrm{p}<0.001)$ with age, body condition and breed of ruminants, which is related with Nibret et al. [18] in Lay-Armacheho Woreda North West of Ethiopia, in which $18.22 \%$ in cattle, $23 \%$ in sheep and $7.3 \%$ in goat with high proportion of Rhipicephalus was found and other finding that reported by Teshome (2002) (16\% in goats and $23.8 \%$ in sheep) in Sidama zone. The relatively low prevalence rate of tick infestation in my study as compared to the above finding might be due to the dry season period during which the study was conducted whereas humidity and prolonged sunlight promote the survival and reproduction of ticks in low land areas [19].

A high prevalence of pediculosis: was noticed in ruminants $(6.34 \%$, $7.21 \%$ and $8.55 \%$ ) for sheep, cattle and goat respectively. The study is associated with findings by Yacob et al. [15] conducted in and around Adama town $6.63 \%$ and $6.10 \%$ in sheep and goats respectively. The pediculosis prevalence observed in the study area was in agreement with previous reports of Haffize [20]. The risk for this skin disease was significantly increased in cross breed cattle and in young and poor body condition ruminants $(\mathrm{p}<0.001)$. By contrast, no significant $(\mathrm{P}>0.05)$ sexual predisposition was evidenced as previously reported by Regasa [21]. As repeatedly reported from Kombolcha and selected area of Amhara region by Abdulhamid [22] and Tefera [23] respectively the prevalence of pediculosis in the respective study was $14.2 \%$ and $39.8 \%$ in small ruminants. Sheep ked was the most abundant parasite of sheep during my study and similar report was done by Ermias [24] in Sebeta, which was high significant association $(\mathrm{P}<0.001)$ with species of animal.

Mange mite infection was registered at prevalence rates of $2.34 \%$ in cattle, $2.38 \%$ in sheep and $3.29 \%$ in goats. The demodicosis prevalences previously reported in cattle ranged from $0.42 \%$ in Nekemte region Regasa [21] to $1.63 \%$ in the Wolaita Soddo region Chalachew [25]. In the previous report from Wolaita Soddo, $0.98 \%$ prevalence of mange in goats and $0 \%$ in sheep were reported [16]. In my study $2.47 \%$ mange positive animal population including sheep was admitted to Gondar university veterinary clinic. The difference in the prevalence of mange in sheep may as a result the difference in management practice in the two study area. However, frequencies of mange in sheep and goats were $0.80 \%$ and $1.37 \%$ respectively in the central Ethiopia Haffize [20] which is less than the prevalence in Gondar town. No significant $(\mathrm{P}>0.05)$ effect of sex, breed and age on the mange mite infection (Demodicosis, Sarcoptosis and Psoroptosis) prevalences in cattle and in small ruminants were observed, but there was significant association
$(\mathrm{P}<0.05)$ between body condition and prevalence of mange mite infection in ruminants. These findings were relatively similar to that reported by Chalachew [21] from Wolaita Soddo region.

The main skin diseases caused by bacteria were Dermatophilosis in the 3 species studied (the prevalence were $1.36 \%, 1.32 \%$ and $0 \%$ in cattle, goats and sheep respectively). The diseases prevalence is less than the prevalence of dermatophilosis in Ambo town with the total prevalence of $5.21 \%$ by Degene et al. [26]. The occurrence of dermatophilosis was mainly in at the beginning of winter during the rainy season. The prevalence of dermatophilosis was significantly associated with season of disease occurrence $(\mathrm{P}<0.001)$, sex of $(\mathrm{p}<0.05)$ in which female cattle were more susceptible than male one. This is accordance with the previous study by Degene et al. [26] in Ambo town; in which dermatophilosis occurs in rainy season and affect female than male. This is suggested as females are always in contact with water for udder washing and they are stressed during milking. In cattle, these rare cases of dermatophilosis were not significantly related to a given risk factor (sex, breed or age) except season of occurrence in agreement with previous reports of Woldemeskel [6]. The dermatophilosis prevalence in local animals was $0.78 \%$ and $0.58 \%$ in cross bred cattle. The prevalence of dermatophilosis is not as much higher in the study area in compared with $1.56 \%$ prevalence in Hawassa Regional state of south nation and nationalities [5]. This might be due to good management system; where cattle are usually kept in door, well sheltered and supplied with appropriate nutritional supplement, as well close follow up for early detection and treatment of diseased animals in Gondar town. Local and cross bred cows for dairy purpose are usually kept by individuals who are relatively educated and have the awareness of animal husbandry and management. This is not commonly practiced by uneducated farmers in the area who essentially rear local animals for traction power. In the current study, low prevalence of dermatophilosis were recorded in goats (1.32\%) compared to cattle $(1.36 \%)$ and are relatively lower than that reported by Haffize [20] (13.07\% in sheep and $2.06 \%$ in goats). The species susceptibility to Dermatophilosis could depend on the natural resistance of the animals and the type of management provided to them.

Lumpy skin disease only found in cattle, which accounts 5.65\% prevalence at Gondar university veterinary clinic; which is higher than the previous study $0.68 \%$ conducted by Yacob et al. [7] at Adama veterinary clinic and lower than the study conducted Wolliso (South west Oromia) which shows a prevalence rate of $27.91 \%$ by Bishawired [27-32]. This is assumed to be as a result of study period, in which multiplication of flies which act as mechanical vector for the virus is common during spring in Ethiopian context and availability of flies for mechanical vector aggravates the infection rate of lumpy skin disease. There was no significant association $(\mathrm{P}>0.05)$ between risk factors and prevalence of Lumpy skin disease except season of disease occurrence which was significantly associated $(\mathrm{P}<0.05)$ with disease prevalence.

The contagious ecthyma/orf (4.91\% in sheep and $9.21 \%$ in goats) and the pox virus disease $(8.55 \%$ in goat and $8.87 \%$ in sheep) were seen in small ruminants. The study conducted in Adama veterinary clinic (1.79\% orf and $11.46 \%$ sheep and goat pox) shows less prevalence than the prevalence here in Gondar; this is suggested that due to difference in the drought level of the area; because contagious ecthyma and sheep and goat pox occurs mostly in drought period. Significant associations between the prevalence of skin diseases induced by orf and small ruminant pox and season of disease occurrence were evidenced in ruminants $(\mathrm{p}<0.05)$. Young animals were also very susceptible to small 
ruminant pox probably because of their young, scarcely wool covered skin and relatively undeveloped immunity as well as their frequent exposure to pasture together with adults and there was statistical significance between age and occurrence of pox and orf disease. On the other hand, the frequency of pox virus disease was relatively elevated compared to other studies [20] who reported $1.53 \%$ in sheep and $1.62 \%$ in goats but by far lower than that reported by Nibret and Basaznew [14] 17.07\% in small ruminants.

\section{Conclusion and Recommendations}

This study was conducted to identify the prevalence of major skin diseases and their associated risk factors on ruminants. The most important skin diseases identified were tick, lice, mange mite, sheep ked, dermatophilosis, lumpy skin disease, sheep and goat pox and contagious ecthyma. Tick was the most abundant ectoparasites in the study area followed by lice, sheep and goat pox, sheep ked, orf, lumpy skin disease and Dermatophilosis. The infestations of skin diseases are important affecting the health and productivity of ruminants in and around Gondar town. Lack of awareness about the significance of the problems among owners for control schemes have contributed to the wide spread nature of skin disease in the area. In view of the significance of skin and hide production as main source of foreign currency to the country and the ever increasing demands of livestock market, the high prevalence of skin diseases prevailing in cattle, sheep and goat in the area requires serious attention to minimize the effect of the problem.

Based on the above conclusion the following Recommendations are forwarded.

Strategic treatment of ruminants with insecticides and acaricides should be practiced in the study area to minimize the impact of ectoparasites on the health of animals.

Awareness creation for the local farmers about the control of skin diseases is essential.

Vaccination should be applied for viral disease before its occurrence season.

Newly introduced animals should be treated before they are introduced in the herd or in to the farm.

Better ruminant animal management practices should be implemented to minimize transmission of the disease and increase the productivity of the animals.

Further detail study should be done to assess the seasonal dynamicity and major ectoparasites borne disease in the study area.

\section{Conflict Interest}

The authors declare that there is no conflict of interest.

\section{References}

1. Central Statistical Agency (CSA) (2013) Agricultural Sample Survey Report On Livestock and Livestock Characteristics. Addis Ababa, Ethiopia pp: 1-188.

2. Ayele S, Assegid W, Orkalemahu MA, Jabbar MM, Ahmed, et al. (2003) Livestock marketing in Ethiopia: A review of structure, performance and development initiatives Socio economics and Policy Research. Livestock Marketing Authority the Federal Democratic Republic of Ethiopia, Addis Ababa, Ethiopia.
3. Sintayehu G, Samuel A, Derek B, Ayele S, Ryan D (2010) Diagnostic study of live cattle and beef production and marketing-Livestock Diagnostics. pp:1-46.

4. Fitaweke M (2012) The Contribution of Livestock to the Ethiopian Economy. IGAD LivestockPolicy 2: 2-11.

5. Addise A, Achenef M (2013) Major Skin Diseases of Cattle: Prevalence and Risk Factors in and around Hawassa, Southern Ethiopia. JAVR 3: 147-153.

6. Woldemeskel M (2000) Dermatophilosis: a threat to livestock production in Ethiopia. Dtsch Tierarztl Wochenschr 107: 144-146.

7. Yacob HT, Yalew TA, Dinka A (2008) Ectoparasite prevalences in sheep, and goats in and around Wolaita Soddo, Southern Ethiopia. Rev Med Vet 9: 450-454.

8. Kaufman PE, Koehler PG, Butler JF (2011) External Parasites on Beef Cattle. University of florida, IFAS extension pp: 1-13.

9. Aiello SE, Mays A (1998) The Merck Veterinary manual. (8thedn) Merck NJ co Inc, white house station: USA.

10. Jones TC, Hunt RD, King NW (1997) Veterinary pathology. (6thedn) Williams and Wilkins (eds) Baltimore, Maryland, USA, pp: 817-872.

11. Cottral GE (1978) Manual of standardized Methods for veterinary Microbiology. Comstic publishing associates a division of university press, London, USA.

12. Ministry of Agriculture, fisheries and food (MAFF) (1977) Manual of Veterinary Parasitological Techniques. Technical bulletin No. 18, Her Majesty's stationary office, London: UK.

13. Agrawa BL (1996) Basic statistics. (3rd edn) Agrawal BL (Ed), Newage Int 1 limited publications.

14. Nibret M, Basaznew B, Tewodros F (2012) Hard Ticks (Ixodidae): Species Composition, Seasonal Dynamics and Body Site Distribution on Cattle in Chilga District, Northwest Ethiopia. University of Gondar,Gondar, Ethiopia.

15. Yacob HT, Nesanet B, Dinka A (2008) Part II: Prevalences of major skin diseases incattle, sheep and goats at Adama Veterinary Clinic, Oromia regional state, Ethiopia. Revue Méd Vét 159: 455-461.

16. Mulugeta Y, Yacob HT, Ashenafi H (2010) Ectoparasites of small ruminants in three selected agro-ecological sites of Tigray Region, Ethiopia. Trop Anim Health Prod 42: 1219-1224.

17. Sertese T, Wossene A (2007) A study on ectoparasite of sheep and goats in eastern parts of Amhara regional state, north east Ethiopia. Small Ruminant Res 69: 62-67.

18. Nibret M, Basaznew B (2012) Assessment of Major Animal Production and Health Problems of Livestock Development in Lay-Armacheho District, North western Ethiopia. AESR 7: 136-141.

19. Radostits OM, Gay C, Hinchcliff KW, Constable PD (2007) A textbook of the diseases of cattle, sheep, goats, pigs and horses. Suanders (10th Edn) Edinburgh, London, pp: 1585-1612.

20. Haffize M (2001) Study on skin disease of small ruminants in central Ethiopia. DVM Thesis, Addis Ababa University, DebreZeit, Ethiopia.

21. Regasa C (2003) Preliminary study on major skin diseases of cattle coming to Nekemte Veterinary Clinic, Western Ethiopia. Addis Ababa University, DebreZeit, Ethiopia.

22. Abdulhamid N (2001) A study on the prevalence of Ectoparasites on live goats, fresh goat pelts and assessment of the skin defect on processed wetblue (picked) goat skins at Kombolcha Tannery, South Wollo Zone, North, and Eastern Ethiopia. DVM Thesis, AAU, FVM, DebreZeit, Ethiopia.

23. Tefera S (2004) Investigation on ectoparasites of small ruminants in selected sites of Amhara regional state and their impact on the tanning Industry, MSc thesis, Addis Ababa University, Ethiopia.

24. Ermias Y (2000) A study on ectoparasites of fresh pelts and assessment of pickled skin defects processed at Sebeta tannery. DVM Thesis, AAU, FVM, DebreZeit, Ethiopia pp: 11-21.

25. Chalachew N (2001) Study on skin diseases in cattle, sheep and goat in and around Wolayta Soddo, Southern Ethiopia. DVM Thesis, Addis Ababa University, DebreZeit, Ethiopia. 
Citation: Teshome D, Derso S (2015) Prevalence of Major Skin Diseases in Ruminants and its Associated Risk Factors at University of Gondar Veterinary Clinic, North West Ethiopia. J Veterinar Sci Technol S: S13-002. doi:10.4172/2157-7579.1000S13-002

Page 7 of 7

26. Dejene B, Ayalew B, Tewodros F, Mersha C (2012) Occurrence of Bovine Dermatophilosis in Ambo Town,WestShoa Administrative Zone, Ethiopia. AEJSR 7: 172-175.

27. Bishawired S (1991) Outbreak of lumpy skin disease in and around Wolliso. DVM Thesis. Addis Ababa University, DebreZeit, Ethiopia.

28. Carter GR (1984) Diagnostic procedures in veterinary bacteriology and mycology. (4th Edn) Thomas CC (ed.) Illinois, USA pp: 431-436.

29. Central Statistical Authority (CSA) (2008) Agricultural sample enumeration report on livestock and farmimplement. IV, Addis Abeba, Ethiopia pp: 26-136.
30. Ferguson JD (2011) Review of body condition scoring dairy herd.

31. Teshome W (2002) Study on small ruminant skin disease in the Sidama Zone, Southern Ethiopia. DVM thesis, Addis Ababa University, Ethiopia.

32. Tewodros F, Fasil W, Mersha C, Malede B (2012) Prevalence of Ectoparasites on Small Ruminants in and Around Gondar Town. Aejsr 7:106-111

33. Walker AA, Bouatour A, Camicas JL, Estadapena AA, Harok IG, et al. (2003) Ticks of domestic animals in Africa: A guide to identification species. The University of Edinburgh, UK. 